\title{
Impact of perioperative hemoglobin levels on postoperative outcomes in gastric cancer surgery
}

\author{
Do-Hyun Jung $\cdot$ Hyuk-Joon Lee $\cdot$ Dong-Seok Han • \\ Yun-Suhk Suh $\cdot$ Seong-Ho Kong $\cdot$ Kuhn-Uk Lee $\cdot$ \\ Han-Kwang Yang
}

Received: 6 March 2012/Accepted: 4 September 2012/Published online: 25 September 2012

(c) The International Gastric Cancer Association and The Japanese Gastric Cancer Association 2012

\begin{abstract}
Background The aim of this study was to evaluate the association of postoperative blood transfusion and anemia with postoperative outcomes in gastric cancer surgery.

Methods We enrolled 588 patients who had undergone curative resection for gastric cancer. Input variables for risk assessment consisted of 3 categories: patient demographics, surgical and pathological factors, and anemia-related factors. Postoperative outcomes included 30-day morbidity and mortality. Univariate and multivariate analyses were performed to identify risk factors influencing postoperative complications.

Results The rate of total complications was $19.0 \%$. Comorbidity, lowest hemoglobin $(\mathrm{Hb})$ level from the operative day up to postoperative day 7 (LOW-Hb), the percentage of drop in $\mathrm{Hb}$ level on postoperative day 2 (POD2-Hb change), and postoperative transfusion were independent risk factors in the multivariate analysis, with LOW-Hb and postoperative transfusion found to be the most significant factors. When LOW-Hb was $\geq 9.0 \mathrm{~g} / \mathrm{dL}$, postoperative complications were higher in the transfused group than in the non-transfused group (60.0 vs. $14.2 \%$, respectively, $p=0.024$ ), but when LOW-Hb was $<9.0 \mathrm{~g} / \mathrm{dL}$, postoperative complications were not different between the 2 groups (44.6 vs. $37.5 \%, p=0.525$ ).
\end{abstract}

D.-H. Jung · H.-J. Lee · D.-S. Han · Y.-S. Suh · S.-H. Kong ·

K.-U. Lee · H.-K. Yang

Department of Surgery, Seoul National University College

of Medicine, Seoul, Korea

H.-J. Lee $(\bowtie) \cdot$ H.-K. Yang

Department of Surgery and Cancer Research Institute,

Seoul National University College of Medicine, Seoul, Korea

e-mail: appe98@snu.ac.kr
Conclusion The lowest postoperative $\mathrm{Hb}$ level and postoperative transfusion were the most significant risk factors for postoperative complications in gastric cancer surgery.

Keywords Anemia $\cdot$ Blood transfusion $\cdot$ Stomach neoplasm

\section{Introduction}

Gastric cancer is the most common malignancy in Korea, Japan, and other Asian countries [1, 2], and it is the second leading cause of death worldwide [3]. The best treatment for gastric cancer is surgical resection. Bleeding is a major postoperative complication after gastric cancer surgery.

Anemia increases complications during the perioperative period [4, 5]. Transfusion is an effective treatment method for anemia [6], and it was thought that transfusion may reduce the rate of anemia-related postoperative complications. However, transfusion itself has some adverse effects including pulmonary complications, graft versus host disease, and the transmission of infectious diseases. Several reports have suggested that the transfusion, and not anemia, increases the risk of postoperative complications $[7,8]$.

However, severe anemia may be fatal [9]; thus, there has been much debate on the risks and the benefits of transfusion. To date, there is no clear evidence as to which of the 3 factors; namely: (1) preoperative anemia, (2) postoperative anemia, and (3) transfusion is the most important indicator of postoperative outcomes.

The present study was conducted to evaluate the association of perioperative anemia status and transfusion with postoperative complications in gastric cancer surgery. 


\section{Patients, materials, and methods}

We retrospectively collected the data of 868 patients who had undergone radical resection for histologically confirmed gastric carcinoma from January 2009 through December 2009 at the Seoul National University Hospital in Korea.

Eligibility criteria included preoperative histologically confirmed gastric adenocarcinoma, curative gastric resection, and standard lymphadenectomy. Curative gastric resection was defined as negative resection margins, enbloc resection of the greater and lesser omentum, and D1 plus or D2 lymph node (LN) dissection. Standard lymphadenectomy was defined as that when the number of retrieved LNs was $\geq 15$ [10].

We excluded patients with distant metastases, those with a previous history of gastrectomy, and those receiving neoadjuvant chemotherapy, as well as those who had undergone combined resection with bypass surgery or open biopsy [11, 12]. Patients who had received preoperative transfusion were also excluded, because the hemoglobin $(\mathrm{Hb})$ level just before the operation is influenced by preoperative transfusion.

Finally, we enrolled 588 patients who had undergone curative resections for gastric cancer for analysis in the present study.

Input variables for risk assessment consisted of 3 categories: patient demographics, surgical and pathological factors, and anemia-related factors. Patient demographics included age, gender, body mass index (BMI), body weight change in the 3 months before the operation, preoperative albumin levels, and comorbidity. Surgical and pathological factors included operation time, approach method (open vs. laparoscopic), operation method, range of LN dissection, and TNM stage (6th edition of American Joint Cancer Committee/International Union Against Cancer staging system). Anemia-related factors included 4 sub-factors: (1) preoperative $\mathrm{Hb}$ (PRE-Hb); (2) percentage drop in the $\mathrm{Hb}$ level on postoperative day 2 (POD2-Hb change), which reflects blood loss during surgery; (3) lowest $\mathrm{Hb}$ from the operative day until postoperative day 7 (LOW-Hb); and (4) postoperative transfusion until postoperative day 7 (the category of postoperative transfusion included 5 patients transfused during the operation).

Postoperative outcomes included 30-day morbidity and mortality (POD30). Complications were graded by the Clavien-Dindo classification [13]. A simple hospital course deviation (grade 1) was not regarded as an event, whereas those requiring medical or surgical interventions (grade 2 or higher) were regarded as events. Morbidity was classified as follows: (1) local complications including wound infection, fluid collection/abscess, anastomosis leakage, stenosis, intestinal obstruction, ileus, intraluminal bleeding, intraabdominal bleeding, and pancreatitis; and (2) systemic complications including pulmonary, renal, urinary, cardiac, and neurologic problems, as defined in our previous study [14-16].

For statistical analysis, SPSS 16.0 (SPSS, Chicago, IL, USA) software was used. Univariate and multivariate logistic regression analyses were performed to identify risk factors influencing postoperative complications. A $p$ value of $<0.05$ was considered statistically significant.

\section{Results}

Patient demographics and operative and pathological characteristics are listed in Table 1. The age and gender

Table 1 Patient factors and surgical and pathological factors

\begin{tabular}{|c|c|}
\hline Variables & Number (percentage) \\
\hline \multicolumn{2}{|l|}{ Age (years) } \\
\hline \multicolumn{2}{|l|}{59.1 (range 29-88) } \\
\hline \multicolumn{2}{|l|}{ Gender (male: female) } \\
\hline \multicolumn{2}{|l|}{ 404: $184(2.2: 1)$} \\
\hline \multicolumn{2}{|l|}{ BMI $\left(\mathrm{kg} / \mathrm{m}^{2}\right)$} \\
\hline$<18.5$ & $21(3.6)$ \\
\hline$\geq 18.5$ & $567(96.4)$ \\
\hline Weight change (3 months) & $86(14.6)$ \\
\hline \multicolumn{2}{|l|}{$<3.3(\mathrm{~g} / \mathrm{dL})$} \\
\hline Comorbidity & $271(46.1)$ \\
\hline \multicolumn{2}{|l|}{ Yes } \\
\hline \multicolumn{2}{|l|}{ Operation time } \\
\hline$<160 \min$ & $265(45.1)$ \\
\hline$\geq 160 \mathrm{~min}$ & $323(54.9)$ \\
\hline \multicolumn{2}{|l|}{ Approach method } \\
\hline Open & $469(79.8)$ \\
\hline Laparoscopy & $119^{\mathrm{a}}(20.2)$ \\
\hline \multicolumn{2}{|l|}{ Operation method } \\
\hline Distal gastrectomy BI & $265(45.1)$ \\
\hline Distal gastrectomy BII & $170(28.9)$ \\
\hline Total gastrectomy & $81(13.8)$ \\
\hline Proximal gastrectomy & $38(6.5)$ \\
\hline Pylorus-preserving gastrectomy & $34(5.8)$ \\
\hline \multicolumn{2}{|l|}{ LN dissection } \\
\hline D1 plus & $95(16.2)$ \\
\hline D2 & $493(83.8)$ \\
\hline \multicolumn{2}{|l|}{ T-stage } \\
\hline EGC & $394(67.0)$ \\
\hline $\mathrm{AGC}$ & $194(33.0)$ \\
\hline \multicolumn{2}{|l|}{$\mathrm{N}$-stage } \\
\hline No & $412(70.1)$ \\
\hline N1 or more & $176(29.9)$ \\
\hline
\end{tabular}

$B M I$ body mass index, $B I$ Billroth type I anastomosis, $B I I$ Billroth type II anastomosis, $E G C$ early gastric cancer, $A G C$ advanced gastric cancer, $L N$ lymph node

a 14 Robotically assisted operations were included 
Table 2 Total complications

\begin{tabular}{lcc}
\hline Complication & Number & Percentage \\
\hline Local & 35 & \\
Wound infection & 16 & 6.0 \\
Stenosis & 12 & 2.7 \\
Fluid collection/abscess & 9 & 2.1 \\
Ileus & 7 & 1.5 \\
Anastomotic leakage & 6 & 1.2 \\
Intraabdominal bleeding & 2 & 1.0 \\
Intestinal obstruction & 2 & 0.3 \\
Pancreatitis & 1 & 0.3 \\
Intraluminal bleeding & & 0.2 \\
Systemic & 13 & \\
Pulmonary problem & 2 & 2.2 \\
Renal problem & 1 & 0.3 \\
Urinary problem & 1 & 0.2 \\
Cardiac problem & 1 & 0.2 \\
Neurologic problem & 4 & 0.2 \\
Others & 112 & 0.6 \\
Total & & 19.0 \\
\hline
\end{tabular}

proportions of the subjects were similar to those in our previous studies $[1,15]$.

Local and systemic complications until POD30 are summarized in Table 2. The rate of total complications was $19.0 \%$, with the percentages of local and systemic complications being 15.0 and $4.0 \%$, respectively. Wound infection $(6.0 \%)$ was the most common local complication. Pulmonary complication $(2.2 \%)$ was the most common systemic complication. There was no mortality before POD30.

Risk factors were analyzed relative to the total complications. Comorbidity, approach method, operation method, T-stage, $\mathrm{N}$-stage, and all of the anemia-related factors, i.e., PRE-Hb, POD2-Hb change, LOW-Hb, and postoperative transfusion were significantly associated with the total complication rate $(p$ value $<0.05)$ as determined by the univariate analysis (Table 3). However, of these, only comorbidity, POD2-Hb change, LOW-Hb, and postoperative transfusion were independently associated with total complications as determined by the multivariate analysis (Table 4).

Among the above 4 independent risk factors, LOW-Hb was further analyzed for the evaluation of the relationship between anemia status and total complications in gastric cancer. The rate of total complications was $23.5 \%$ when the LOW-Hb was between 9 and $10 \mathrm{~g} / \mathrm{dL}$. But the rate increased to $37.1 \%$, when the LOW-Hb was between 8 and $9 \mathrm{~g} / \mathrm{dL}$, suggesting that a LOW-Hb level of $9 \mathrm{~g} / \mathrm{dL}$ could be used as the cut-off value.
Table 3 Univariate analysis of risk factors for complications

\begin{tabular}{|c|c|c|c|}
\hline Variable & No. & Cx. rate (no.) & $p$ value \\
\hline Overall & 588 & $19.0 \%(112)$ & \\
\hline \multicolumn{4}{|l|}{ Age (years) } \\
\hline$<60$ & 291 & $17.2 \%(50)$ & \multirow[t]{2}{*}{0.294} \\
\hline$\geq 60$ & 297 & $20.9 \%(62)$ & \\
\hline \multicolumn{4}{|l|}{ Gender } \\
\hline Male & 404 & $16.8 \%(68)$ & \multirow[t]{2}{*}{0.054} \\
\hline Female & 184 & $23.9 \%(44)$ & \\
\hline \multicolumn{4}{|l|}{ BMI } \\
\hline$<18.5 \mathrm{~kg} / \mathrm{m}^{2}$ & 21 & $28.6 \%(6)$ & \multirow[t]{2}{*}{0.260} \\
\hline$\geq 18.5 \mathrm{~kg} / \mathrm{m}^{2}$ & 567 & $18.7 \%(106)$ & \\
\hline \multicolumn{4}{|l|}{ Weight change (3 months) } \\
\hline Absent & 502 & $19.5 \%(98)$ & \multirow[t]{2}{*}{0.554} \\
\hline Present & 86 & $16.3 \%(14)$ & \\
\hline \multicolumn{4}{|l|}{ Albumin } \\
\hline$<3.3 \mathrm{~g} / \mathrm{dL}$ & 11 & $36.4 \%(4)$ & \multirow[t]{2}{*}{0.234} \\
\hline$\geq 3.3 \mathrm{~g} / \mathrm{dL}$ & 577 & $18.7 \%(108)$ & \\
\hline \multicolumn{4}{|l|}{ Comorbidity } \\
\hline No & 317 & $15.1 \%(48)$ & \multirow[t]{2}{*}{0.011} \\
\hline Yes & 271 & $23.6 \%(64)$ & \\
\hline \multicolumn{4}{|l|}{ Operation time } \\
\hline$<160 \min$ & 265 & $21.1 \%(56)$ & \multirow[t]{2}{*}{0.248} \\
\hline$\geq 160 \mathrm{~min}$ & 323 & $17.3 \%(56)$ & \\
\hline \multicolumn{4}{|l|}{ Approach } \\
\hline Open & 469 & $21.1 \%(99)$ & \multirow[t]{2}{*}{0.013} \\
\hline Laparoscopy & 119 & $10.9 \%(13)$ & \\
\hline \multicolumn{4}{|l|}{ Operation method } \\
\hline Partial gastrectomy & 507 & $17.0 \%(86)$ & \multirow[t]{2}{*}{0.002} \\
\hline Total gastrectomy & 81 & $32.1 \%(26)$ & \\
\hline \multicolumn{4}{|l|}{ LN dissection } \\
\hline D1 plus & 95 & $13.7 \%(13)$ & \multirow[t]{2}{*}{0.156} \\
\hline D2 & 493 & $20.1 \%(99)$ & \\
\hline \multicolumn{4}{|l|}{ T-stage } \\
\hline EGC & 394 & $15.2 \%(60)$ & \multirow[t]{2}{*}{0.001} \\
\hline AGC & 194 & $26.8 \%(52)$ & \\
\hline \multicolumn{4}{|l|}{$\mathrm{N}$-stage } \\
\hline No & 412 & $16.5 \%(68)$ & \multirow[t]{2}{*}{0.021} \\
\hline N1 or more & 176 & $25.0 \%(44)$ & \\
\hline PRE-Hb & & & \\
\hline $\mathrm{Hb} \geq 13 \mathrm{~g} / \mathrm{dL}(\mathrm{M}), \geq 12 \mathrm{~g} / \mathrm{dL}(\mathrm{F})$ & 463 & $17.3 \%(80)$ & 0.040 \\
\hline $\mathrm{Hb}<13 \mathrm{~g} / \mathrm{dL}(\mathrm{M}),<12 \mathrm{~g} / \mathrm{dL}(\mathrm{F})$ & 125 & $25.6 \%(32)$ & \\
\hline POD2-Hb change & & & \\
\hline Change $\leq 20 \%$ & 424 & $16.3 \%(69)$ & 0.007 \\
\hline Change $>20 \%$ & 164 & $26.2 \%(43)$ & \\
\hline LOW-Hb & & & \\
\hline $\mathrm{Hb} \geq 9.0 \mathrm{~g} / \mathrm{dL}$ & 494 & $14.8 \%(73)$ & $<0.001$ \\
\hline $\mathrm{Hb}<9.0 \mathrm{~g} / \mathrm{dL}$ & 94 & $41.5 \%(39)$ & \\
\hline
\end{tabular}


Table 3 continued

\begin{tabular}{|c|c|c|c|}
\hline Variable & No. & Cx. rate (no.) & $p$ value \\
\hline \multicolumn{4}{|c|}{ Postoperative Tf } \\
\hline No & 527 & $15.9 \%(84)$ & $<0.001$ \\
\hline Yes & 61 & $45.9 \%(28)$ & \\
\hline
\end{tabular}

Boldface items indicate $p$ values of $<0.05$

$C x$ complication, $B M I$ body mass index, $E G C$ early gastric cancer, $A G C$ advanced gastric cancer, $H b$ hemoglobin, $P R E-H b$ preoperative hemoglobin, POD2-Hb change percentage drop in the $\mathrm{Hb}$ level on postoperative day 2, $\mathrm{LOW}-\mathrm{Hb}$ lowest $\mathrm{Hb}$ from the operative day until postoperative day $7, T f$ transfusion

Table 4 Multivariate analysis of risk factors for complications

\begin{tabular}{lrrl}
\hline Variable & $p$ value & \multicolumn{1}{l}{ OR } & $95 \%$ CI \\
\hline Approach (open) & 0.362 & 0.736 & $0.381-1.422$ \\
$\begin{array}{l}\text { Operation method (total } \\
\text { gastrectomy) }\end{array}$ & 0.189 & 1.497 & $0.820-2.734$ \\
T-stage (AGC) & 0.151 & 1.534 & $0.855-2.750$ \\
N-stage (N1 or more) & 0.842 & 0.941 & $0.515-1.717$ \\
PRE-Hb (Hb $<13$ g/dL (M), & 0.441 & 0.801 & $0.455-1.409$ \\
$\quad<12$ g/dL (F)) & & & \\
Comorbidity (yes) & $\mathbf{0 . 0 1 9}$ & 1.682 & $1.090-2.595$ \\
POD2-Hb change $(>20 \%)$ & $\mathbf{0 . 0 0 6}$ & 1.933 & $1.203-3.104$ \\
LOW-Hb (Hb $<9.0$ g/dL) & $<\mathbf{0 . 0 0 1}$ & 3.693 & $2.114-6.450$ \\
Postoperative Tf $($ yes) & $<\mathbf{0 . 0 0 1}$ & 3.458 & $1.888-6.332$
\end{tabular}

Boldface items indicate $p$ values of $<0.05$

$A G C$ advanced gastric cancer, $H b$ hemoglobin, $P R E-H b$ preoperative hemoglobin, POD2-Hb change percentage drop in the $\mathrm{Hb}$ level on postoperative day $2, \mathrm{LOW}-\mathrm{Hb}$ lowest $\mathrm{Hb}$ from the operative day until postoperative day $7, O R$ odds ratio, $C I$ confidence interval, $T f$ transfusion

Table 5 Relationship between LOW-Hb and complications according to transfusion

\begin{tabular}{llc}
\hline LOW-Hb & Cx. rate (Cx. no/total no.) & $p$ value \\
\hline $\mathrm{Hb} \geq 9.0 \mathrm{~g} / \mathrm{dL}$ & & 0.024 \\
$\quad$ Transfusion: no & $14.2 \%(69 / 487)$ & \\
Transfusion: yes & $60.0 \%(3 / 5)$ & 0.372 \\
$8.0 \mathrm{~g} / \mathrm{dL} \leq \mathrm{Hb}<9.0 \mathrm{~g} / \mathrm{dL}$ & & \\
$\quad$ Transfusion: no & $37.1 \%(13 / 35)$ & 0.999 \\
Transfusion: yes & $52.9 \%(9 / 17)$ & \\
$\mathrm{Hb}<8.0 \mathrm{~g} / \mathrm{dL}$ & & \\
Transfusion: no & $40.0 \%(2 / 5)$ & \\
Transfusion: yes & $41.0 \%(16 / 39)$ & \\
\hline
\end{tabular}

$C x$ complication, $L O W-H b$ lowest $\mathrm{Hb}$ from the operative dayuntil postoperative day 7

Among the 4 independent risk factors, LOW-Hb and postoperative transfusion were found to be the most significant. When the LOW-Hb was $\geq 9.0 \mathrm{~g} / \mathrm{dL}$, postoperative complications were higher in the transfused group as compared with the non-transfused group (60.0 vs. $14.2 \%$, $p=0.024)$, but when the LOW-Hb was $<9.0 \mathrm{~g} / \mathrm{dL}$, postoperative complications were not different between the 2 groups (44.6 vs. $37.5 \%, p=0.525$ ) (Table 5).

\section{Discussion}

The purpose of the present study was to evaluate the association of perioperative anemia status and transfusion with postoperative outcomes in gastric cancer surgery.

The relationship between perioperative anemia and postoperative complications remains controversial. Some studies have shown that perioperative anemia increases the rate of postoperative complications $[4,5]$, whereas others have shown that mild anemia does not affect the rate of postoperative complications [8].

Many studies have shown adverse effects of transfusions [8] on several kinds of complications [17, 18], including an increased recurrence of gastric cancer [19]. However, some studies showed no relationship between transfusion and postoperative complications [20, 21]. However, transfusions are an essential treatment method in cases of massive bleeding [22]. These controversial findings imply that the $\mathrm{Hb}$ level can be used as an indicator for transfusion [9].

In the present study, comorbidity, POD2-Hb change, $\mathrm{LOW}-\mathrm{Hb}$, and postoperative transfusion were found to be independent risk factors for postoperative complications, suggesting that both anemia and transfusion are important factors in the development of complications after gastric cancer surgery. However, subgroup analysis according to postoperative transfusion revealed a relationship between LOW-Hb and complications. In the postoperatively nontransfused subgroup, the complication rate decreased as LOW-Hb increased (complication rates: $40.0 \%$ at LOW$\mathrm{Hb}<8 \mathrm{~g} / \mathrm{dL}, 37.1 \%$ at LOW-Hb between 8 and $9 \mathrm{~g} / \mathrm{dL}$, and $14.2 \%$ at LOW-Hb $\geq 9.0 \mathrm{~g} / \mathrm{dL}$ ). In contrast, in the postoperatively transfused subgroup, the complication rate increased as LOW-Hb increased (complication rates: $41.0 \%$ at LOW-Hb $<8 \mathrm{~g} / \mathrm{dL}, 52.9 \%$ at LOW-Hb between 8 and $9 \mathrm{~g} / \mathrm{dL}$, and $60.0 \%$ at LOW-Hb $\geq 9.0 \mathrm{~g} / \mathrm{dL}$ ). However, it should be noted that only 5 patients with $\mathrm{Hb} \geq 9$ $\mathrm{g} / \mathrm{dL}$ were transfused. Usually blood transfusion is not mandatory in patients with $\mathrm{Hb} \geq 9 \mathrm{~g} / \mathrm{dL}$. There was no evidence of active bleeding in these 5 patients with $\mathrm{Hb}$ $\geq 9 \mathrm{~g} / \mathrm{dL}$. A Gem Premier blood gas/electrolyte analyzer (GEM Premier 3000, Bedford, Massachusetts, USA) showed a rapid $\mathrm{Hb}$ decrease (GEM Hb level; 7.1-8.3 g/dL) in these patients. The PRE-Hb range in these 5 patients was 9.7-14.3 g/dL. Transfusion was initiated according to the GEM results. However, routine complete blood counts (CBCs) showed that the Hb level was 9.9-11.1 $\mathrm{g} / \mathrm{dL}$. The 
transfusion was stopped after the $\mathrm{CBC}$ results were reported. Two of these 5 patients received 1 pint of red blood cell transfusion during the operation and the other 3 patients received 1 or 2 pints of red blood cell transfusion after the operation. One patient transfused during the operation had a wound infection. And two of the patients transfused after the operation had complications; a neurologic problem and fluid collection. There were no problems during the operation in these five patients.

In agreement with previous studies $[8,23]$, the present study shows that the $\mathrm{Hb}$ level could be used as an indication for transfusion. Thus, we suggest that clinicians should have different treatment strategies according to the LOW$\mathrm{Hb}$ level. As the complication rate was associated with transfusion in patients with $\mathrm{Hb}>9.0 \mathrm{~g} / \mathrm{dL}$, transfusion should be initiated cautiously in these patients.

Transfusion should be initiated according to the patient's status, including vital signs and evidence of bleeding, and not as per their $\mathrm{Hb}$ level. However, Vlaar et al. [24] showed that the decision to perform RBC transfusions in practice was predominantly based on the $\mathrm{Hb}$ level rather than on a patient's status. Ansari and Szallasi [23] proposed that using the $\mathrm{Hb}$ level as an indicator for transfusion could reduce blood utilization. Therefore, by providing a cut-off value, the results of the present study may help reduce blood utilization.

One of the limitations of this study is that it was retrospective and did not record data on intraoperative blood loss in all the patients. However, we found a positive correlation (correlation coefficient $=0.64$ ) between POD2-Hb change and intraoperative blood loss in the 106 patients for whom these data were available (data not shown), which suggested that POD2-Hb change may reflect intraoperative blood loss.

LOW-Hb may be a reflection of preoperative nutritional status as well as intraoperative blood loss. However, in our study nutritional factors including body weight change in the 3 months before the operation, and preoperative albumin levels were not significantly associated with total complications in the univariate analysis. POD-2 $\mathrm{Hb}$ change, reflecting intraoperative blood loss, was found to be an independent risk factor for postoperative complications. These findings suggest that the effect of nutritional status on LOW-Hb is not significant.

A higher rate of severe anemia has been reported in patients in the advanced stage than in the early stage of gastric cancer [12]. Therefore, we excluded patients with distant metastasis, previous gastrectomy history, neoadjuvant chemotherapy, and combined resection, thus ensuring more homogeneity of subjects in terms of complexity of the operation.

It is difficult to define transfusion-related complications. Direct transfusion-related complications include pulmonary complications, compromised immune status, and the transmission of infectious diseases. However, some studies have reported several other transfusion-related complications $[15,16]$. In our study, we only analyzed complications that developed up to postoperative day 30 ; thus excluding those that could likely not be attributable to the acute effects of transfusion.

The present study has the limitations of being retrospective and of having a relatively small sample size. Therefore, future prospective large-scale studies are necessary.

In conclusion, the postoperative lowest $\mathrm{Hb}$ level and postoperative transfusion were the most significant risk factors for postoperative complications in gastric cancer surgery.

\section{References}

1. Lee HJ, Yang HK, Ahn YO. Gastric cancer in Korea. Gastric Cancer. 2002;5(3):177-82.

2. Matsuda A, Matsuda T. Time trends in stomach cancer mortality (1950-2008) in Japan, the USA and Europe based on the WHO mortality database. Jpn J Clin Oncol. 2011;41(7):932-3.

3. Jung KW, Shin HR, Kong HJ, Park S, Won YJ, Choi KS, et al. Long-term trends in cancer mortality in Korea (1983-2007): a joinpoint regression analysis. Asian Pac $J$ Cancer Prev. 2010;11(6):1451-7.

4. Leichtle SW, Mouawad NJ, Lampman R, Singal B, Cleary RK. Does preoperative anemia adversely affect colon and rectal surgery outcomes? J Am Coll Surgeons. 2011;212(2):187-94.

5. Hare GM, Baker JE, Pavenski K. Assessment and treatment of preoperative anemia: continuing professional development. Can J Anaesth. 2011;58(6):569-81.

6. Yuruk K, Bartels SA, Milstein DM, Bezemer R, Biemond BJ, Ince $\mathrm{C}$. Red blood cell transfusions and tissue oxygenation in anemic hematology outpatients. Transfusion. 2011;52:641-6 .

7. Bennis M, Parc Y, Lefevre JH, Chafai N, Attal E, Tiret E. Morbidity risk factors after low anterior resection with total mesorectal excision and coloanal snastomosis: retrospective series of 483 patients. Ann Surg. 2012;255:504-10.

8. Bernard AC, Davenport DL, Chang PK, Vaughan TB, Zwischenberger JB. Intraoperative transfusion of $1 \mathrm{U}$ to $2 \mathrm{U}$ packed red blood cells is associated with increased 30-day mortality, surgical-site infection, pneumonia, and sepsis in general surgery patients. J Am Coll Surg. 2009;208(5):931-7, 7 e1-2 (discussion $8-9)$.

9. Carless PA, Henry DA, Carson JL, Hebert PP, McClelland B, Ker $\mathrm{K}$. Transfusion thresholds and other strategies for guiding allogeneic red blood cell transfusion. Cochrane Database Syst Rev. 2010;(10):CD002042.

10. Japanese Gastric Cancer Association. Japanese gastric cancer treatment guidelines 2010 (ver. 3). Gastric Cancer. 2011;14(2): $113-23$.

11. Songun I, Putter H, Kranenbarg EM, Sasako M, van de Velde CJ. Surgical treatment of gastric cancer: 15 -year follow-up results of the randomised nationwide Dutch D1D2 trial. Lancet Oncol. 2010;11(5):439-49.

12. Hoya Y, Takahashi T, Saitoh R, Anan T, Sasaki T, Inagaki T, et al. Blood transfusion requirement for gastric cancer surgery: reasonable preparation for transfusion in the comprehensive health insurance system. Int J Surg. 2008;6(3):234-7. 
13. Dindo D, Demartines N, Clavien PA. Classification of surgical complications: a new proposal with evaluation in a cohort of 6336 patients and results of a survey. Ann Surg. 2004;240(2):205-13.

14. Kim HH, Hyung WJ, Cho GS, Kim MC, Han SU, Kim W, et al. Morbidity and mortality of laparoscopic gastrectomy versus open gastrectomy for gastric cancer: an interim report-a phase III multicenter, prospective, randomized Trial (KLASS Trial). Ann Surg. 2010;251(3):417-20.

15. Ahn HS, Lee HJ, Yoo MW, Jeong SH, Park DJ, Kim HH, et al. Changes in clinicopathological features and survival after gastrectomy for gastric cancer over a 20-year period. Br J Surg. 2011;98(2):255-60.

16. Bae HJ, Lee HJ, Han DS, Suh YS, Lee YH, Lee HS, et al. Prealbumin levels as a useful marker for predicting infectious complications after gastric surgery. J Gastrointest Surg. 2011; 15(12):2136-44.

17. Napolitano LM, Kurek S, Luchette FA, Anderson GL, Bard MR, Bromberg W, et al. Clinical practice guideline: red blood cell transfusion in adult trauma and critical care. J Trauma. 2009;67(6):1439-42.

18. Xenos ES, Vargas HD, Davenport DL. Association of blood transfusion and venous thromboembolism after colorectal cancer resection. Thromb Res. 2011;129:568-72.
19. Yamashita K, Sakuramoto S, Kikuchi S, Katada N, Kobayashi N, Watanabe M. Transfusion alert for patients with curable cancer. World J Surg. 2007;31(12):2315-22.

20. Argalious MY, Dalton JE, Mascha EJ, Cywinski JB, Clair DG. Association of red blood cell transfusion and postoperative outcomes after endovascular aortic repair. Semin Cardiothorac Vasc Anesth. 2011;15(1-2):49-55.

21. Bortul M, Calligaris L, Roseano M, Leggeri A. Blood transfusions and results after curative resection for gastric cancer. Suppl Tumori. 2003;2(5):S27-30.

22. Rainer TH, Ho AM, Yeung JH, Cheung NK, Wong RS, Tang N, et al. Early risk stratification of patients with major trauma requiring massive blood transfusion. Resuscitation. 2011;82(6):724-9.

23. Ansari S, Szallasi A. Blood management by transfusion triggers: when less is more. Blood Transfus. 2011;4(1):1-6.

24. Vlaar AP, In der Maur AL, Binnekade JM, Schultz MJ, Juffermans NP. Determinants of transfusion decisions in a mixed medical-surgical intensive care unit: a prospective cohort study. Blood Transfus. 2009;7(2):106-10. 